\title{
REFORMA PORTUÁRIA, TRABALHO E AÇÃO SINDICAL: O EXEMPLO DO PORTO DE ITAJAÍ-SC - 2000-2016
}

\author{
Gabriel de Souza BOZZANO*
}

\begin{abstract}
RESUMO: A proposta do artigo é avaliar o impacto de políticas públicas sobre o setor portuário brasileiro a partir do ciclo de reformas iniciado nos anos 2000, tomando como exemplo o caso do porto de Itajaí-SC. Especificamente, a intenção é demostrar o papel dos trabalhadores e sindicatos para a contestação dos efeitos mais nocivos dos processos de privatização portuária em curso nessa cidade. Analisamos como os sindicatos portuários construíram novas formas de cooperar e propor novas formas de organizar seus trabalhos, atuando, desse modo, para o direcionamento da política local de desenvolvimento portuário.
\end{abstract}

PALAVRAS-CHAVE: Reforma portuária. Trabalho. Sindicalismo.

\section{Introdução}

Neste artigo, apresentamos o estudo de caso do porto de Itajaí-SC como um exemplo das lutas por trabalho e manutenção dos investimentos nas regiões portuárias que se intensificaram no país a partir da política de privatização dos portos dos anos 2000 (MONIÉ; VIDAL, 2006).

Desde a primeira década do século XXI, registrou-se uma maior demanda para portos que se utilizem de estruturas mais especializadas - tendência observada por Cocco e Silva (1999) sobre o atual papel integrador dos portos em grandes cadeias globais de produção. O formato de corredor de produtos, típico da era fordista, cede espaço ao porto como promotor de territórios produtivos, ou seja, um espaço que possui capacidade latente de agregar valor a produtos e serviços de empresas atuantes em nível global.

\footnotetext{
* UFRJ/PPGSA - Universidade Federal do Rio de Janeiro. Programa de Pós-Graduação em Sociologia e Antropologia. Rio de Janeiro - RJ - Brasil. 20051-070 - gabrielbozzano@hotmail.com.

http://orcid.org/0000-0002-8034-5556.
} 
No caso do porto de Santos, por exemplo, houve um decréscimo na participação das cargas especializadas de $37 \%$, em 1990, para $27 \%$ em 2015. Essa evidencia traz à tona os limites para o desenvolvimento local e regional dos portos da era fordista, em razão dos diminutos efeitos multiplicadores registrados para a cidade de Santos, em São Paulo (MONIÉ; VIDAL, 2006). Em contrapartida, em termos de valor agregado, os Portos de Itajaí-SC e Navegantes-SC, que formam o complexo portuário de Itajaí-SC, geraram 10\% do PIB nacional, em 2015 (MIGUEL; SOUZA, 2017).

Logo, chamamos a atenção para uma tendência de crescimento rápido dos portos de média estatura, como o de Itajaí-SC, que ampliaram seus potenciais de manuseio de cargas. Houve grandes incentivos para a abertura de portos de estrutura mediana, que, de outro modo, estão sujeitos a uma maior concorrência e captura de cargas conteinerizadas das mesorregiões - ou seja, portos que não se distanciem mais do que de um raio de $200 \mathrm{~km}$ (MONIÉ; VIDAL, 2006; COLONETI; ZILLI; GOULARTI FILHO, 2014).

O porto de Itajaí-SC, assim como outros do país que alcançaram o status de porto mediano viram de forma concomitante uma "fuga de cargas" - do ponto de vista das localidades que sediam os portos, a opção de armadores em escolherem portos de tarifas mais baratas - que, em seu caso, apontou para uma média de 50\% das cargas ao porto privado em Navegantes (LABTRANS; 2015).

A imagem (Figura 1) nos ajuda a visualizar o avanço dos conflitos no porto de Itajaí-SP. Reflexo do novo movimento do capital e da reconfiguração das relações de produção com a concomitante intensa privatização dos portos públicos no país desde os anos 2000 (DOCTOR, 2017).

$\mathrm{O}$ ano de 2008 foi um momento marcante para o porto de Itajaí-SC. Durante esse período, a Agência Nacional de Transportes Aquaviários (ANTAQ) concedeu anuência à operação do porto privado para que a ação fosse realizada na área do porto organizado $^{1}$, em Navegantes-SC. Esta região deveria ser, em tese, exclusivamente destinada aos portos públicos. A ocupação foi considerada ilegal pela Autoridade Portuária de Itajaí e pelos órgãos fiscalizadores, como a ANTAQ. Em consequência, o porto perdeu parte de sua renda devido à fuga de cargas e ao não pagamento de taxas por parte dessas estruturas à administração. Da mesma forma, inúmeros trabalhadores perderam seus postos no mercado de trabalho (BRASIL, 2008).

\footnotetext{
1 Esse conceito é uma figura jurídica que define a jurisdição dos portos públicos, do uso e dos custos associado à manutenção de infraestrutura aquática, assim como a contratação de trabalhadores sindicalizados.
} 
Figura 7 - Porto de Itajaí-SC e terminal de Navegantes-SC

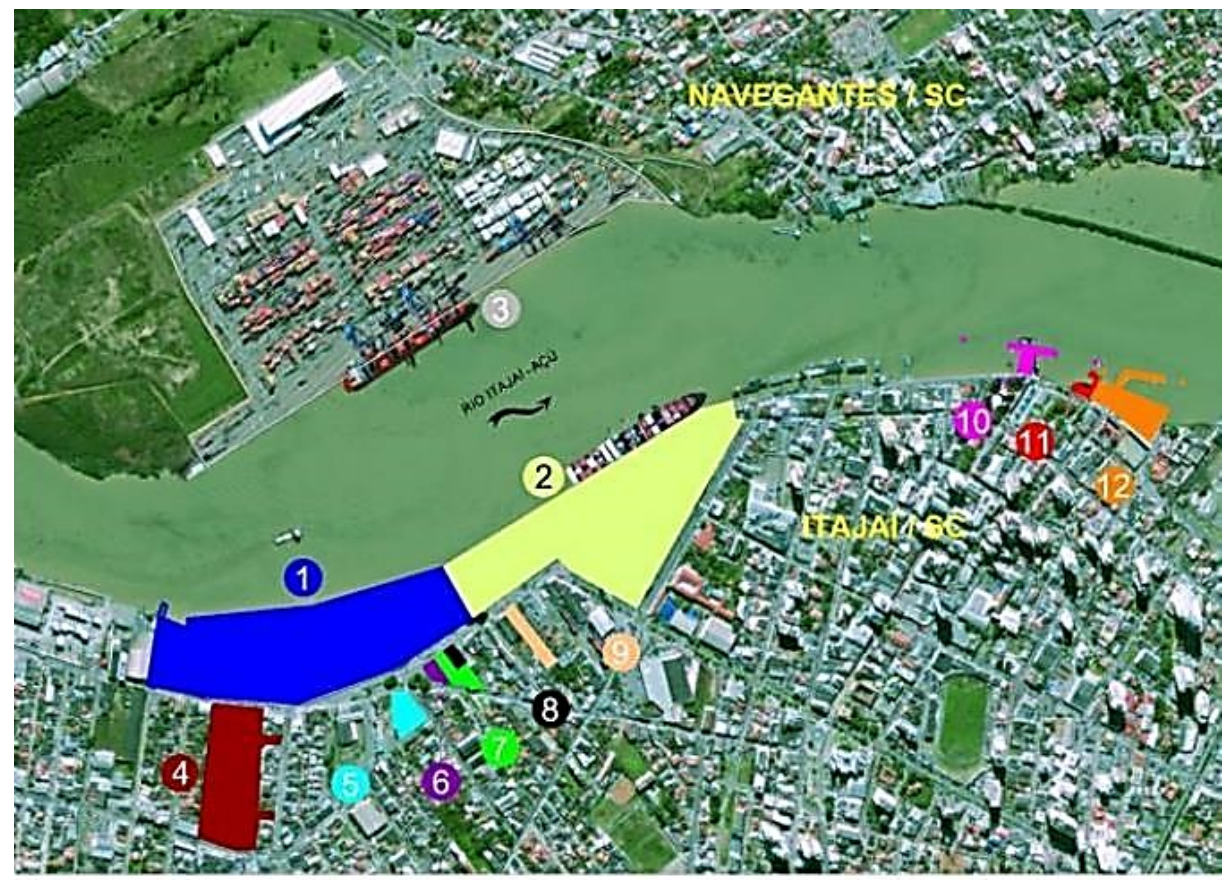

\section{LEGENDA}

(1) Porto de Itajai - Area Primária

2 Porto de Itajai - Área Arrendada

(3) TUP Portonave

(4) Recinto Alfandegado Contiguo

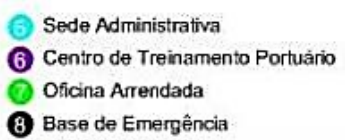

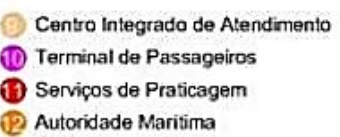

Centro Integrado de Atendimento

11) Servicos de Praticagem

(12) Autoridade Maritima

Fonte: Labtrans (2015)

A situação demandou respostas dos órgãos estatais, como a participação dos trabalhadores para que pudessem visibilizar e alçar suas presenças em ações contestatórias contrárias à privatização. Desde 2008 até 2016, os trabalhadores, os sindicatos e a autoridade portuária local que entrevistamos estavam atentos para a realidade de outros portos em nível nacional, que perderam, ou seus status de portos públicos, ou suas condições de portos economicamente viáveis (DIÉGUEZ, 2014).

Nesse contexto de privatização dos portos, o Estado se aproveitou da fragilidade do movimento sindical e intensificou a transferência de estruturas de mediação das relações produtivas ao setor privado, que existiam anteriormente sob a lógica de estruturas de representação locais dos trabalhadores, do Estado e do setor patronal.

De um lado, com a privatização dos portos e com a quebra do monopólio da força de trabalho pelos sindicatos, Doctor (2017) indica que foram produzidos efeitos 
adversos aos que eram esperados pelo governo federal: a) a liberalização intensificou a precarização do trabalho - e não necessariamente o racionalizou; b) houve uma ocupação desordenada de áreas portuárias públicas e c) a volatilidade dos ciclos comerciais com armadores deslocou as cargas para os portos concorrentes.

Por outro lado, fica patente a falta de uma política nacional unificada para os portos, que nos anos 2000 trouxe uma novidade às pesquisas sobre trabalho e sindicalismo portuário: apontamos para uma perda de unidade da ação empresarial próprivatização dos portos, já que os principais exportadores foram satisfeitos em seus pleitos já na primeira rodada de privatização durante os anos 1990 (DOCTOR, 2017).

Nossa premissa é a de que os trabalhadores e os sindicatos se colocaram atentos a esses conflitos e às mudanças institucionais, que se estenderam ao território sob a influência do porto de Itajaí e que se apoiaram em novas legislações no campo do direito do trabalho para influírem sob novos processos laborais e de distribuição do trabalho mais democrático, bem como no desenvolvimento da política local para o porto de Itajaí-SC (CAVALHO; COSTA, 2015). O entendimento, construído no intervalo de tempo entre 2008 e 2016, foi o de que somente em conjunto os sindicatos portuários poderiam ter alguma expectativa de benefício futuro, tendo em vista o desmantelamento em curso do porto público de Itajaí-SC.

Propomos analisar uma experiência de reconversão das trajetórias de trabalho dos portuários, pautadas pela exclusão do porto público no destino comum do complexo portuário de Itajaí. Nossa hipótese é a de que com um capital político reativado em um momento de aguda crise econômica (2008-2016), os trabalhadores foram capazes de influir amplamente na defesa de direitos e do desenvolvimento local.

Analisamos quais alternativas se abriram para vinte trabalhadores entrevistados que transitaram entre o emprego precário, na condição de celetista no porto privado e do seu retorno ao porto público como trabalhadores avulsos ${ }^{2}$.

\section{A nova ofensiva contra o trabalho portuário brasileiro no século XXI}

As instituições do corporativismo portuário que sustentaram um tipo específico de ação sindical e das relações com o empresariado ainda são indispensáveis para refletirmos sobre o futuro do trabalho e dos portos (DIÉGUEZ, 2014; RODRIGUES,

\footnotetext{
${ }^{2}$ Trabalhador que possui reserva de mercado garantida em área de porto público, remuneração se dá mediante o chamado e a disponibilidade de trabalho, com funções específicas e restritas ao sindicato que faz parte.
} 
1991). Essas instituições permitiram que, por meio de canais institucionalizados ${ }^{3}$ de interlocução, o papel do Estado no controle das relações capital/trabalho via a mediação da Justiça do trabalho fosse reforçado.

O que se viu, durante os anos 1990, foi que o sistema closed shop entra na pauta do empresariado com seu lobby para o avanço das reformas e privatizações. De qualquer forma, esse é o momento em que o Estado diminui sua participação na regulação do trabalho portuário, caminhando para a composição de um novo sistema de regulação do trabalho ainda regido pelo corporativismo portuário, contudo, o mesmo agora fortemente vinculado ao ritmo e às demandas do mercado.

Partimos da ideia de que as relações entre capital e trabalho nos portos partem daquelas instituições da era corporativistas, ao menos na medida em que alguns de seus ganhos são motivos eficientes para a mobilização dos sindicatos (BARROS, 2017, p.80).

Apontamos que a Lei no 8.630, de 25 de fevereiro de 1993 (BRASIL, 1993), marco da modernização portuária no Brasil, alterou substancialmente as relações, tanto com sindicatos, que perderam o monopólio sobre o controle de trabalho passando para o Órgão Gestor de Mão de Obra (OGMO), como criou figuras jurídicas no sentido de facilitar a liberalização desse mercado.

Ademais, os modelos de privatização dos portos baseados em concessão de área pública e autorização em área fora dessa delimitação avançam com um sistema dual, de comercialização e corporativização, com a implementação de Conselhos de Autoridade Portuária ${ }^{4}$ (CAPS) e, ao mesmo tempo, o Estado transforma as Cias Docas em empresas de economia mista, mantendo rígido controle sobre as autoridades portuárias ao indicar diretores e regulando suas atividades.

Da mesma forma, o trabalho e sua modernização sob o signo da flexibilização - que nesse contexto dá-se o multifuncionalidade - elimina, mas não consegue suprimir as diferenças entre as categorias de trabalhadores ao nomeá-las por apenas uma: trabalhador portuário avulso. Estivadores, consertadores, guindasteiros, operários portuários e conferentes deixariam de existir e estariam todos sob essa única nomenclatura caso a flexibilização fosse aplicada conforme os estritos interesses do empresariado.

\footnotetext{
${ }^{3}$ Os trabalhadores ainda devem ser sindicalizados para poderem ser contratados para o trabalho. Esse sistema é conhecido como closed shop, onde o acesso ao mercado de trabalho é restrito apenas aos trabalhadores sindicalizados.

${ }^{4}$ Atua nas questões de desenvolvimento da atividade portuária, promoção da competição, proteção do meio ambiente e de formação dos preços dos serviços portuários.
} 
Com a nota técnica ํํำ 036, emitida pelo Ministério do Trabalho e Emprego, temos o parecer sobre as formas adequadas de interpretação da evolução das relações de trabalho nos portos. Ela aponta que a Lei, no 8.630/1993 estabelece-se, com o art. 18, que os "operadores portuários [empresários marítimos] devem constituir, em cada porto organizado, um órgão gestor de mão de obra" (RIO DE JANEIRO, 2001, p.1).

Ela entende que o OGMO pode somente efetuar o dimensionamento do trabalho a partir de convenções ou acordos coletivos de trabalho. É desse ponto de vista que não somente o OGMO, mas o próprio Porto Organizado definem os limites e os canais pelos quais as condições de trabalho, composição de equipes de trabalho (também chamado de "ternos") e remuneração serão estabelecidas.

A nota técnica $\mathrm{n}^{\mathrm{0}} 036$ interpreta que, para além do que se estabelece ao OGMO como prerrogativa de definir o número de vagas para acesso ao registro do trabalhador portuário avulso, cabe ao Conselho de Supervisão desse órgão - entidade tripartite, com representantes dos trabalhadores, empresários e Estado - deliberar sobre esses assuntos. (RIO DE JANEIRO, 2001).

A pergunta que essa nota lança é: o que se entende por "número de vagas" para a adaptação da força de trabalho aos portos? A resposta à "essa questão é simples deslinde, uma vez que a competência para dimensionar o quantitativo de trabalhadores ou 'quadros' sempre esteve regulada na legislação anterior a 1993" (RIO DE JANEIRO, 2001, p.2).

O Decreto-Lei no 3, de 27/01/66 em seu art. 5 define que cabe às Delegacias de Trabalho Marítimo (DTM) fixar "o número necessário de trabalhadores para o respectivo serviço em armazéns e no cais. [...] Os portos deveriam obedecer às diretrizes desse órgão e efetuar as [...] matrículas até o limite fixado, anualmente" (RIO DE JANEIRO, 2001, p.2).

O ponto essencial aqui é traçado com a noção de "limite" imposta pelo Estado. Ao ser superada a média de 100 horas de trabalho, aumenta-se o número de trabalhadores para reestabelecer a média anterior (SARTI, 1981). Apesar desse entendimento, a nota técnica não responde à Legislação $\mathrm{n}^{-} \mathrm{0}$ 8.630/93, que confere ao trabalhador avulso portuário somente a preferência na contratação, e não à exclusividade do mercado de trabalho defendida.

Com a intensificação da reforma portuária nos anos 2000, a questão do dimensionamento da força de trabalho não poderia ficar em aberto. A consequente queda do rendimento médio dos trabalhadores comprometeria "a precisão do art. 2 da Convenção no 137 da OIT, que estabelece a necessidade de uma renda mínima a ser estabelecida aos avulsos portuários" (RIO DE JANEIRO, 2001, p.3). 
A questão do vínculo empregatício se apresentou como uma possibilidade de dimensionamento da força de trabalho que não favoreceu, concluímos, somente o empresariado. Essa cessão pode e foi negociada entre os sindicatos portuários de Itajaí$\mathrm{SC}$, transformando o interesse de "vinculamento" (termo nativo que se refere ao trabalho por tempo indeterminado) por alguns trabalhadores como alternativa ao subemprego.

Nesse contexto, com a intensificação da privatização dos portos nacionais, a partir de 2008 avança-se, em Itajaí-SC, o desejo por trabalho e um acordo favorável com os patrões. De outro lado, como a legislação permitiu a redução da força de trabalho nos portos, a negociação iniciada entre as partes favoreceu a iniciativa de subutilizar/subempregar os trabalhadores com vagas remanescentes de outros sindicatos.

Essa situação deu margem para a aplicação arbitrária do seguinte princípio de flexibilização, que, teoricamente, deveria passar pela negociação do sindicato sem ferir o mecanismo de suplência, ou seja, do trabalho aos sindicalizados os quais após terem sido chamados ao trabalho entram para o fim de uma lista de chamada (ZOTTO, 2002).

Os desafios para a manutenção desse sistema ficam melhor expostos na seguinte afirmação:

Havendo falta de mão de obra, ou recusa injustificada em comparecer ao trabalho por parte de alguma categoria, será aplicada a multifuncionalidade, facultando-se aos TPAs (Trabalhador portuário avulso) habilitados (que possuem curso extensivo a categoria com postos de trabalho a serem preenchidos), se engajarem para o trabalho, devendo ser requisitados pelo OGMO, tudo de acordo com o disposto neste instrumento coletivo. (SANTA CATARINA, 2011, n.p.).

A lógica dos empresários foi bem simples nesse sentido - que, como veremos em seguida, durou até 2013 com a nova legislação, "Cortamos o cadastrado e mantemos o registrado" (diretor, 40 anos, OGMO). É comum a opinião de que o OGMO se apresente muitas vezes "fechado com o patrão" (estivador, 65 anos, aposentado).

Entrevistado: os armadores não repassaram o dinheiro para o treinamento, daí a gente fez caixa e apresentamos para o patrão o trabalhador com uma qualificação

\footnotetext{
5 O registrado "é o reserva do cadastrado" (capatazia, 35 anos). A lógica é de chamar o primeiro da fila até que ela termine, para daí avançar sobre os reservas do cadastro, ou seja, titulares a chamada dentro de uma fila sequencial. Esse é o ponto fundamental das lutas pela flexibilização do trabalho e ação sindical portuária.
} 
nova. Daí eles quiseram negociar com a gente. Eles entendem dessa forma: você tem que ter forças para ser ouvido. (Estivador, sindicalista, 45 anos).

Vemos com esse relato que a fixação dos quadros é resultado do poder negocial das partes, tendo o sindicato como ator indispensável nesse processo. Apontamos algumas diferenças da política de concessão com a Legislação no 8.630/93 (BRASIL, 1993) e seus desdobramentos em relação ao trabalho portuário. O porto organizado e os sindicatos dos trabalhadores avulsos se destacam, nesse contexto, porque são eles que põem em prática o fato de que os acordos e as convenções coletivas devam prevalecer nas negociações também frente aos terminais privados e públicos.

A realização de licitação no setor portuário, tipicamente caracterizada como monopólio natural, era entendida como aquela que resultasse na proposta mais vantajosa para a administração pública, leia-se: mais dividendos em troca das concessões para operações portuárias por empresas privadas.

A noção de bem público para um funcionário da autoridade portuária (44 anos, fiscal) é "bastante restritiva por que o que define um valor para o cidadão? Mais bens de consumo ou a função que o porto executa para toda a economia?". Ele aponta que “com a Legislação no 12.815/13 as cargas precisam ser comprovadas que irão, de fato, agregar valor à cidade de Itajaí”.

Trata-se de enfatizar que, para haver autorização, deve-se comprovar que os investimentos manterão os trabalhadores portuários avulsos inscritos, proporcionalmente, nos portos privados.

Antes da Legislação $\mathrm{n}^{\mathrm{o}}$ 12.815/13 (BRASIL, 2013), o uso de trabalhador vinculado (contratação por tempo indeterminado) entrava na mesma categoria do "trabalhador portuário avulso" defendida pelo empresariado. Segundo um entrevistado: "chamavam a gente para os terminais privados, e como a renda era menor lá, aqui no porto público teve mais pressão para ceder não só no salário, mas para maior contratação por tempo indeterminado" (estivador, sindicalista, 66 anos,).

Segue que a Legislação n⿳0 12.815/13 transformou o OGMO como entidade solidária financeiramente com o empresariado. Portanto, avançamos com o entendimento de que, a partir dessa legislação, os interesses unilaterais do empresariado foram contrabalanceados com os do OGMO.

Nesse sentido, remetemos a um entrevistado (capatazia, 38 anos). Em sua opinião, tanto o OGMO como o Porto Organizado são instituições indispensáveis à defesa do trabalho portuário avulso. 
Se fosse depender deles [empregadores], seria claramente um retrocesso. Mas ainda bem que o porto público está aí para isso: a administração do porto estipula o horário de funcionamento e as jornadas de trabalho, que para a gente é de 6 horas ininterruptas no cais do porto. É por isso, também, que a gente sabe em que momento o contrato começa e termina: o trabalhador bateu o ponto dentro do porto, tá valendo. (Capatazia, 38 anos).

Podemos ver como o Porto Organizado sustenta as pretensões por avanço na defesa de direitos dos trabalhadores. Discutiremos, em seguida, como, a partir dessa inserção específica no campo do direito do trabalho, este foi instrumentalizado a partir dos avanços da legislação para a luta por trabalho digno. O ponto é que esses trabalhadores se mantiveram atentos às formas explícitas, como também sutis de flexibilização em curso porque as mesmas atingem todo o porto público ao trazerem imensa precarização do trabalho (KREIN, 2007).

\section{Estratégias sindicais e inovações do trabalho portuário}

Os trabalhadores mais jovens, que possuíam entre 25 a 45 anos, foram os que buscaram emprego como vinculados (trabalho por tempo indeterminado) no porto privado (Portonave), em Navegantes-SC. Suas experiências no porto privado foi uma forma de avaliarmos como eles entendiam suas oportunidades associadas à qualificação de seus ofícios no porto público.

A respeito à idade dos trabalhadores, os dados disponibilizados pelo diretor do OGMO (40 anos) afirmam que em 2016, 70\% da força de trabalho no porto público possuía ensino médio ou superior, completo e incompleto. Anteriormente, "essa porcentagem era de $40 \%$ até o ano de 2001" (diretor, 45 anos, OGMO). Essa frequência é maior entre os mais jovens, até 49 anos.

O ofício, no sentido que lhe atribuímos, é tanto um "saber-fazer", ou seja, um trabalho transmitido entre operários de mesma formação e faixa etária e aprendido no chão de fábrica; como é um posto sobre a trajetória de trabalho, de um pertencimento no porto público como um valor a ser defendido. Logo, refletimos sobre exemplos de reconversão bem-sucedidos do trabalho portuário. Esses exemplos referem-se à socialização do trabalho dos "antigos", pertencentes à geração anterior, como da qualificação para o trabalho dos mais novos, que disputam a liderança nos sindicatos e nos postos de trabalho mais remunerados (SILVA, 1995). 
Essa relação ainda se faz presente e é relevante por apresentar aos mais novos a estrutura das relações produtivas vigentes, com seus macetes para manuseio de carga e do papel do sindicato em suas vidas. Inspiramo-nos em Dubar (2005), que discorre sobre uma dinâmica de identificação para si e para o outro dos trabalhadores de ofício. São trabalhadores mais jovens, que possuem forte vínculo com os processos de aprendizado no trabalho. Nesse caso, a mobilidade dos portuários é posta à prova pela "busca de um emprego melhor em um mesmo setor ou tipo de atividade, por valorização da experiência (aumento da mobilidade com a idade), e [ou] a busca de um emprego melhor por falta de perspectiva no setor (mobilidade intensa já no início da carreira)" (DUBAR, 2005, p.243).

Não podemos nos referir ao mercado de trabalho portuário como aberto, no sentido de um potencial ilimitado de sua reinvenção ou como no modelo de competências explorado pelas empresas marítimas e OGMO. No limite, esse mercado de trabalho é dual, no sentido que Piore (2008) atribui ao termo, com mobilidade interna restrita a alguns poucos trabalhadores que, ao escolherem se aventurar no mercado externo - porto privado, Portonave - custos estão associados à sua permanência e ao seu retorno ao porto público.

É interessante observar a faixa etária média dos trabalhadores avulsos no porto público que passam pela intermediação do OGMO. O porto público possui $38 \%$ dos trabalhadores com 50 anos ou mais, $37 \%$ entre 40 e 49 e apenas $25 \%$ têm menos de 39 anos. Nos terminais privados, $56 \%$ dos trabalhadores estão na faixa dos 25 aos 39 anos, $14 \%$ dos 18 aos 24 e 30\% estão acima dos 50 anos. Sobre a formação educacional, $70 \%$ dos trabalhadores possuem ensino médio completo.

No período da pesquisa de campo, no porto público junto à tendência de diminuição da idade média dos trabalhadores, "estimulou-se o começo de programas de demissão voluntária” (gerente, 45 anos, OGMO). Assim, temos o quadro

[...] que era no ano 2000 de 1132 trabalhadores portuários. Em 2009 foram aposentados 107 estivadores, até 2017 foram aposentados no total 317 trabalhadores de todas as categorias; até 2015 houve cancelamentos de cadastro por punição de 139 pessoas, punidas por transgressões diversas no porto e fora dele; falecidos tivemos 76 pessoas; em 2014 foram 54 estivadores que entraram com o programa voluntário de cancelamento. (Gerente, 45 anos, OGMO).

Houve uma "saída grande de trabalhadores com mais de 20 anos de carreira, com pequena escolaridade, e o surgimento de trabalhadores com maior escolaridade" (diretor, 45 anos, OGMO). 
Entre 2008 e 2016, rapidamente, em razão do uso de métodos flexíveis de trabalho, os trabalhadores mais jovens viram que não teriam rendimento garantido. Nesse cenário, os trabalhadores relataram-nos que, na medida em que se aumenta a idade e a falta de qualificação emitida por órgão interno ao porto (OGMO), aumenta-se os riscos para manterem uma renda mínima, considerada digna para seus padrões. Isso porque "a qualificação adquirida em porto privado não vale em porto público" (estivador, 37 anos).

Como nos diz um estivador (35 anos) “o problema é o seguinte: não perdemos nossos cadastros, mas quando retornamos nossos cursos feitos lá em Navegantes (no Portonave) não valem aqui no porto de Itajaí".

Rapidamente esses trabalhadores perceberam que o sindicato se apresentou como um canal importante da promoção da solidariedade para novos processos de trabalho. Para que isso seja possível, o OGMO precisou se tornar um aliado dos trabalhadores. Um estivador (38 anos) que tinha ficado afastado do porto público, diz: "porque se você trabalha via o OGMO, você tem ainda acesso às qualificações reatualizações, né, sempre tem, estiva básica 1, 2, 3, 4, 5".

A pressão por emprego, entretanto, mudou o cenário, e o trabalho que é "nobre" (que paga mais) é pensado como acesso a progressão na carreira. Lembramos que o trabalhador pode escolher pegar o trabalho, oferecido ou não. Desse modo, a distinção entre trabalho nobre e não-nobre, típico da era do sindicato closed-shop foi ressignificado. Isso explicaria a demanda dos sindicatos e a razão de muitos trabalhadores "pegarem também trabalho que paga menos, na expectativa de terem acesso garantido ou constante a trabalho mais remunerado" (capatazia, 45 anos). Segundo um entrevistado (estivador, 35 anos):

Daí a gente vai pegando curso e mais curso, não falta um dia, foram anos que a gente entregou a alma para essa empresa aí... Então, é o seguinte: somente agora que consegui o certificado para maquinário, que não tem a ver com a qualificação, mas tempo de serviço. Paga mais, né. Então, acho que a situação era ruim, mas pode ser pior. Não quero ter que sair daqui porque continua a opção para vários companheiros.

Um trabalhador da capatazia (35 anos), reitera a mesma posição:

Claro, não falta trabalho para a gente, mas isso não quer dizer que depois vai sobrar. Estamos chegando nesse entendimento de que podemos abrir vagas de transferência interna, o que facilita a vida dos nossos e dos trabalhadores dos 
outros sindicatos que não tem emprego, mas também que o imposto de origem volte para os sindicatos.

Essa postura indica que o vinculado cumpre uma função estratégica para o sindicato, desde que em aparelhos que envolvam maior tendência e formação profissional. "Então, antes era uma briga para entrar no guindaste. Muitos não sabem mexer nele, e outros querem somente porque paga melhor. Daí não aparecem depois no porto" (capatazia, 42 anos).

Entrevistador: Então é bom ter mais qualificação para ter acesso a trabalho?

Entrevistado: Quando tem demanda grande de trabalho, os próprios vinculados não dão conta. Tem muito horário disponível. Aí chama no sindicato da terrestre para fazer essa função que é do vinculado também na falta de horário e período deles.

O entendimento anterior era o de que o vinculado e o trabalho precário minam o poder de barganha dos trabalhadores (BARROS, 2017; DIEGUEZ, 2014), mas ele avança para uma dimensão mais ampla, abarcando as dinâmicas mais complexas de trabalho em curso no porto de Itajaí. Isso fica explícito nos seguintes pensamentos:

Entrevistado: Tem que saber mexer num guindaste a bordo, não é coisa para todos, não. Então, o que a APM fez, pagou 10.000 para um cara e fixou ele nessa posição de guindasteiro. Daí eles selecionaram alguns dos melhores, o que o sindicato aprovou, meio que desaprovando. Não tinha escolha, né. Não poderiam dizer em assembleia que teve seleção por debaixo dos panos, porque daí vai cair nos mesmos problemas que tô te falando. Não vai para frente, não adianta.

Entrevistador: Então, o que acontece que é bom para o sindicato desse esquema todo?

Entrevistado: É o seguinte, quando aumenta muito o serviço, entra e sai navio, eles precisam folgar porque o porto funciona 24 horas. Daí eles chamam o avulso do sindicato. (Estivador, 37 anos).

Essa pressão contra os trabalhadores, especialmente os mais jovens, tensionou a relação com os que têm mais de 45 anos de idade. Entende-se a preocupação dos mais novos em relação aos mais velhos, visto que estes "não foram pressionados a pegar tudo quanto é tipo de curso" para manterem-se empregados (estivador, 40 anos).

Desta forma, muitos trabalhadores mais velhos "teriam se contentado com o que recebem" (estivador, 33 anos). Como nos diz um gerente (40 anos, OGMO): “Os 
trabalhadores que adquiriram novas qualificações, que estão em dia, posso te dizer que são poucos, são os mais jovens [...] que no total dos 150 trabalhadores da estiva, uns 40 pegam firme, estão dispostos a fazer a multifuncionalidade e usar o que aprenderam."

Segundo um entrevistado (estivador, 41 anos), "[os mais velhos] não precisam vir que nem eu ao porto pra pagar as contas. E também acho que eles não estão tão bem preparados para operar o maquinário que tem aí no porto".

Da parte dos mais velhos, inúmeras vezes os trabalhadores mais jovens foram acusados de "afrontar o sindicato porque legitimariam o pleito da Portonave [porto privado] de burlar o sistema de contratação pelo OGMO" (Eduardo Gutera, presidente da Federação Nacional dos Portuários).

Essa "afronta", em nosso entendimento, marca mais explicitamente as diferenças geracionais em curso. Ao buscarem por trabalho dentro do porto se qualificando, e mesmo fora dele se vinculando, os trabalhadores mais jovens nos relataram a necessidade de terem uma experiência que condiz com as relações de trabalho em curso.

A situação de encontrar um trabalho digno, no contexto da crise do porto público, esbarrou na baixa divisão do trabalho predominante no porto privado, que possui somente três funções definidas: estivador, capatazia e conferente. Logo, os trabalhadores avulsos do porto público viram que a expectativa de alcançar melhor rendimento em razão do desempenho, peça fundamental de suas experiências de trabalho, não os permitiram investir em maior qualificação profissional nesse espaço do porto privado. Esse contraste ajuda-nos a entender as opções abertas a esses trabalhadores no seu retorno ao porto público.

Como um mercado interno que vem lutando para se preservar e inovar frente as demandas do capital, a novidade do trabalho portuário está, em nosso entendimento, na taxa maior de mobilidade sem mudança de status em relação às experiências passadas (SENNETT,1999). Os que permanecem, sobrevivem ao processo de enxugamento, mas isso não é uma vantagem frente as lógicas de alianças e sociabilidade para manter-se empregado no porto, as quais passam também pelos sindicatos portuários.

O conflito geracional se abre, nesse sentido, explicitamente ao trabalho em atividade conexa para o sindicato da estiva, que sofreu mais com o processo de enxugamento e racionalização do trabalho portuário. A atividade conexa é bastante limitada, geralmente há de uma à duas vagas nos trabalhos terrestres de apoio para que o trabalhador dos estivadores no navio se viabilize ${ }^{6}$. A limitação originava conflitos

\footnotetext{
${ }^{6}$ Guindaste e motorista de caminhão são as mais comuns para os estivadores, que trabalham no navio, mas operam eventualmente estas funções.
} 
entre os trabalhadores, que disputavam o trabalho considerado do sindicato de origem da capatazia. É neste sentido que a reclamação acontece: “então, eu sou multifuncional, tenho todos os cursos e pego uma vez por mês o trabalho de conexão, igual ao pessoal que não vêm para o porto [referindo-se aos mais velhos] "'" (estivador, 36 anos).

Chamamos atenção para o ano de 2008, com início das operações do porto privado. $\mathrm{O}$ trabalho da estiva desestabiliza a escala de trabalhadores. "Muitos foram para lá para o Portonave" (estivador, 41 anos). Os trabalhadores da estiva buscavam o trabalho em lingada (trabalho da capatazia) e operador (trabalho da capatazia). Estas funções sofrem um corte profundo a partir do ano 2008 e intensifica a experiência de expulsão dos que detém menor qualificação.

Ilustramos a experiência de expulsão a partir da Tabela 1, que aponta para a dimensão da oferta de trabalho e engajamento para os trabalhadores avulsos.

Tabela 1 - Oferta de trabalho e engajamento

\begin{tabular}{|c|c|c|}
\hline Atividade & Ofertados & Engajados \\
\hline Arrumador & 30897 & 22404 \\
\hline Bloco & 7585 & 2695 \\
\hline Conferente & 2580 & 2597 \\
\hline Consertado & 1385 & 433 \\
\hline Estiva & 8289 & 17857 \\
\hline Vigia & 1984 & 1155 \\
\hline Total & 52720 & 47141 \\
\hline
\end{tabular}

Fonte: OGMO (2008), elaborada pelo autor.

Esta tabela demostra que os estivadores precisaram acessar o trabalho oferecido, necessariamente, de outros sindicatos. Porém, para esses trabalhadores, essa situação se justificou a partir da inflação na oferta do trabalho de capatazia. A consequente perda de poder dessa categoria, assim como de todos os trabalhadores, intensificou a experiência de afastamento com os quadros internos ao sindicato e os aproximou com outros sindicatos desejosos de responder a essa situação de precarização do trabalho.

A entrada no trabalho da capatazia pelos estivadores, de um lado, os aproximou aos interesses da capatazia em avançar com sistemas mais democráticos de trabalho. A respeito disso, um estivador (38 anos) nos relata:

Foi deles (armadores e porto) atacarem pela estiva, é lá que a força do sindicalismo se manteve, é lá que o corte foi mais duro: a conexão, o trabalho em funções

\footnotetext{
${ }^{7}$ Isso acontece porque a idade é um dos critérios para a seleção dos trabalhadores.
} 
terrestres que fazíamos foram suprimidas porque as máquinas "comeram” espaço, e os terrestres, a legislação tava ruim até a pouco tempo, foram. A turma ficou sem emprego, e tem se rebelado e somado forças com a capatazia. A ideia é fechar um acordo coletivo nos próximos anos com todos os trabalhadores. Em Vitória-ES já é, há muito tempo, assim.

Como fica demostrado na fala do entrevistado, justifica-se a necessidade de uma boa relação com a capatazia para as atividades conexas: "tem momento em que o lançamento de mercadorias da terra para o navio precisa de todos os trabalhadores" (estivador, 38 anos). Essa experiência cria laços de continuidade da qual eles são altamente carregados de sentido em ciclos econômicos em queda.

Existe, nesse sentido, um processo de luta pela relevância dos sindicatos de origem (de cada sindicato para a reserva de seu mercado) contra a precarização. Isso, entretanto, somente se visibiliza quando avaliamos o registro das qualificações adquiridas no porto - entre colegas e com a luta pelo domínio relativo dos processos de seleção, definição de jornadas - e as cruzamos com a chamada para o trabalho.

Na Tabela 2 podemos ver como o sistema de distribuição do trabalho tem sido alterado a partir da demanda dos próprios trabalhadores.

Tabela 2 - Interessados na mudança de registro sindical

\begin{tabular}{|c|c|c|}
\hline Sindicato de origem & Total de trabalhadores & Sindicato de destino \\
\hline Sindicato dos estivadores & 19 & Sindicato dos Arrumadores \\
\hline Sindicato dos consertadores & 3 & Sindicato dos Arrumadores \\
\hline Sindicato do Bloco & 2 & Sindicato dos Arrumadores \\
\hline
\end{tabular}

Fonte: (OGMO, 2018), elaborada pelo autor.

Esses dados nos informam que há o interesse e o predomínio dos trabalhadores da estiva em migrarem para o sindicato dos arrumadores e capatazia que detêm uma grande oferta de trabalho oferecido. A proposta do sindicato da capatazia em receber esses trabalhadores é fruto de seu interesse em normatizar o acesso ao registro do trabalho.

Há trabalhadores que entendem o acesso ao trabalho de outra categoria como fonte de renda complementar. Associamos essa posição aos trabalhadores que não iniciaram um processo intensivo de aproximação com os outros sindicatos. Segundo um sindicalista:

Os trabalhadores avulsos geralmente não queriam se vincular, né, é difícil isso, eles não vão se vincular para trabalhar em tractor (caminhão de transporte de 
contêiner) porque daí eles vão ganhar uma miséria. Então, o que aconteceu é que abriu a brecha para eles contratarem fora do OGMO - caso se eles não se interessassem pela oferta dos operadores portuários ou não preenchessem os requisitos exigidos para o cargo oferecido. (Estivador, 50 anos).

Podemos ver uma visão de mudanças nos sindicatos:

Sabes o ATT (tractor)? O caminhãozinho que vem para retirar e colocar os contêineres dos guinchos. Eles chamam para vincular no ATT. Só que como o salário é muito baixo, é o mais baixo que tem. Nem todo terresteiro (capatazia) vai para o ATT. Aí sobra para cá. Daí a gente pode entrar, pode vincular. Depois deles. Esse que é meu veneno... Eu sou operador de guindaste, operador de ponte. Nunca vou ser vinculado. Não tem oportunidade para eu entrar. Estamos finalizando um acordo com os outros sindicatos, daqui há pouco fechamos com todos. (Estivador, 32 anos).

Essa situação trouxe respostas ambivalentes dos sindicatos, especialmente da estiva, no sentido de justificar a prática de flexibilização do trabalho. Ela é ambivalente porque, como diz o entrevistado (estivador, 39 anos): "a gente entendeu como razoável até porque não dava mais para colocar um cara que não sabe operar guindaste como candidato, né?".

A pressão entre os próprios trabalhadores para comparecerem ao serviço da "lingada", trabalho da capatazia em que se paga pouco, intensificou-se, registrando ausência de falta ao trabalho. Comparando com os dados históricos da "lingada" eles sugerem que os trabalhadores da estiva que não tinham acesso aos trabalhos melhores remunerados e de melhor qualificação começaram a demandar uma nova proposta de sistema de rodízio.

Esse mecanismo de distribuição do trabalho, o rodízio, precisou ir além dos seus limites convencionais (SARTI, 1981). Os mecanismos para efetuar essa nova proposta baseiam-se em abrir esse cadastro, já mencionado, mas devolver ao sindicato de origem o imposto que esses trabalhadores recolhem enquanto funcionários de outros sindicatos. Um assalariado da capatazia relata:

Irá revolucionar nosso mercado. Vai ser difícil eles imporem tudo o que eles estão acostumados a fazer. Tem um problema que permanece, mas isso vai passar: não praticamos a multifuncionalidade porque o número de trabalhadores (do sindicato dos estivadores) deles é muito pouco. Não quer dizer que temos que esperar o patrão fazer isso pela gente. (Capatazia, 40 anos). 
Pelas falas dos entrevistados é possível inferir que as principais regras que definem os rumos da organização do trabalho, da definição do perfil desejado - com cursos de qualificação exigidos para o trabalho - e para a multifuncionalidade, não são autoaplicáveis, uma vez que eles precisam passar pela negociação e acordos coletivos. A luta dos sindicatos passa por uma mudança de estratégia e de cultura laboral. Eles não esperam mais por um período de maior demanda e pela manutenção da lógica anterior de trabalho porque seus registros e a própria viabilidade do mercado de trabalho podem ser postas em risco, caso eles não assumam essa posição.

\section{Considerações finais}

A proposta deste artigo foi discutir a trajetória institucional das reformas que acometeram os portos brasileiros a partir do estudo de caso do porto de Itajaí-SC. Esse porto se destaca entre os diversos casos de precarização do trabalho e privatização em curso dos portos no país.

A reflexão pautou-se, inicialmente, pela análise da trajetória da reforma portuária com o foco na primeira década dos anos 2000. Vimos que o Estado se apresentou como um ator protagonista para a indução de novas formas de regulação do mercado do trabalho.

Percebemos um aprendizado intempestivo nos portos da periferia do sistema nacional para novas formas de organização do trabalho. A inserção do movimento sindical no campo do Direito tem absorvido o novo entendimento da jurisprudência portuária, com reflexos diretos sobre os novos mecanismos de intervenção sobre a estrutura portuária local. Esse acumulado de práticas sindicais na periferia do sindicalismo portuário, nos anos 2000, teve o intuito de realçar os acordos coletivos como meio de legitimar os pleitos dos sindicatos para o uso da multifuncionalidade, permitindo uma nova estrutura de oportunidades para ação sindical portuária.

Logo, com as mudanças na lógica de distribuição do trabalho, deduzimos todo um processo de construção de solidariedade intersindical que se mostrou responsiva às demandas empresariais, portanto, interrompendo a interferência desse ator sobre a organização e autonomia do sindicato. A cultura portuária foi ressignificada nesse processo, trazendo a combatividade notória para o plano das múltiplas frentes que extrapolam a vida portuária num contexto de reformas desse setor. 


\section{PORT REFORM, WORK AND UNION ACTION: \\ THE EXAMPLE OF ITAJAÍ PORT, SC, BRAZIL - 2000-2016}

ABSTRACT: The purpose of the article is to evaluate the impact of public policies on the Brazilian port sector, based on a reform cycle started in the years 2000s, taking as an example the case of the port of Itajai, SC, Brazil. In fact, the intention is to demonstrate the role of workers and Unions when contesting the most damaging effects of port privatization processes. We analyzed how the port unions built new ways to cooperate and propose alternative forms for organizing their work, thus also acting to guide the local port development policy

KEYWORDS: Port Reform. Job. Unionism.

\section{REFORMA PORTUARIA, TRABAJO Y ACCIÓN SINDICAL: EL EJEMPLO DEL PUERTO ITAJAÍ-SC - 2000-2016}

RESUMEN: La propuesta del artículo es evaluar el impacto de las políticas públicas en el sector portuario brasileño a partir del ciclo de reformas reforma iniciado en la década de 2000, tomando como ejemplo el caso del puerto de Itajai-SC. Específicamente, la intención es demostrar el papel de los trabajadores y los sindicatos en la lucha contra los efectos más perjudiciales de los procesos de privatización portuaria en curso en esa ciudad. Analizamos cómo los sindicatos portuarios construyeron nuevas formas de cooperar y propusieron nuevas formas de organizar su trabajo, actuando asi para guiar la política de desarrollo portuario local.

PALABRAS CLAVE: Reforma portuaria. Trabajo. Sindicalismo.

\section{REFERÊNCIAS}

BARROS, Thiago Pereira de. Os estivadores do Porto de Santos/SP: uma análise geográfica sobre o trabalho, o sindicato e a modernização dos portos. Orientador: Marcelo Dornelis Carvalhal. 2017. 236 p. Dissertação (Mestrado) - Universidade Estadual Paulista, Presidente Prudente, 2017.

BRASIL. Lei no 12.815 de 05 de junho de 2013. Dispõe sobre a exploração direta e indireta pela União de portos e instalações portuárias e sobre as atividades desempenhadas pelos 
operadores portuários; altera as Leis $\mathrm{n}^{\text {os }} 5.025$, de 10 de junho de $1966,10.233$, de 5 de junho de 2001, 10.683, de 28 de maio de 2003, 9.719, de 27 de novembro de 1998, e 8.213, de 24 de julho de 1991; revoga as Leis $n^{\text {os }} 8.630$, de 25 de fevereiro de 1993, e 11.610, de 12 de dezembro de 2007, e dispositivos das Leis ${ }^{\text {os }} 11.314$, de 3 de julho de 2006, e 11.518, de 5 de setembro de 2007; e dá outras providências. Brasília, 2013. Disponível em: http://www.pla nalto.gov.br/ccivil_03/_ato2011-2014/2013/Lei/L12815.htm. Acesso em: 25 dez. 2017.

BRASIL. AUTOS n. 01674-2008-047-12-00-5. TERMO DE AUDIÊNCIA. Poder Judiciário. Justiça do trabalho. Tribunal regional do trabalho da 12 região. $3^{\mathrm{a}}$ vara do trabalho de Itajaí/SC. 2008.

BRASIL. Decreto legislativo ${ }^{\circ} 29$, de 22 de dezembro de 1993. Lei de modernização dos portos. Brasília, DF, Disponível em: http://www.trtsp.jus.br/geral/tribunal2/LEGIS/ CLT/OIT/OIT_137.html. Acesso em: 25 mai. 2016.

CARVALHO, Francisco Edivar; COSTA, Silvia Pires Bastos. Abordagem prática do trabalho portuário avulso. São Paulo: Ltr, 2015.

COCCO, Giusepe; SILVA, Gerardo. (Orgs.). Cidades e portos: os espaços da globalização. Rio de Janeiro: DP\&A, 1999.

COLONETI, R. A.; ZILLI, J. C. Z.; GOULARTI FILHO, A. A utilização de terminais retroportuários no porto de Itajaí-SC para o escoamento da produção das empresas exportadoras do sul de Santa Catarina. Seminário de Ciências Sociais Aplicadas. Unesc: Criciúma, 2014.

DIEGUEZ, Carla Regina Mota Alonso. Trabalho à deriva: contradições e ambiguidades nas lutas e percepções dos estivadores de Santos (1993-2013). Orientador: José Dari Krein. 2014. 374 p. Tese (Doutorado) - Universidade Estadual de Campinas, Campinas, 2014.

DOCTOR, Mahrukh. Business-State Relations in Brazil: Challenges of the Port Reform Lobby. New York: Taylor and Francis (Routledge), 2017.

DUBAR, Claude. A construção das identidades sociais e profisssionais. São Paulo: Martins Fontes, 2005.

KREIN, José Dari. Tendências recentes nas relações de emprego no Brasil: 1990-2005. Orientador: Carlos Alonso Barbosa de Oliveira, 2007. 347 p. Tese (Doutorado) - Universidade Estadual de Campinas, Campinas, 2007.

LABTRANS. Plano mestre do porto de Itajaí: Cooperação técnica para apoio a SEP/PR planejamento do setor portuário brasileiro e na implantação dos projetos de inteligência logística. Florianópolis: UFSC, 2015.

MIGUEL, Talita Acordi; SOUZA, Maria Helena. Estudo da movimentação portuária do porto de Itajaí no período de 2005-2015. I Congresso Sul Catarinense de Administração e

Comércio Exterior. Criciúma, p.1-13, 2017. 
MONIÉ, Frédéric; VIDAL, Soraia Maria do S. C. Cidades, portos e cidades portuárias na era da integração produtiva. Revista de Administração Pública. Rio de Janeiro, v.40, n. 6, p.975995, nov/dez. 2006.

OGMO. Órgão de Gestão da Mão de Obra Portuária: Itajaí-SC. 2008-2018 Disponível em: http://www.ogmoitajai.com.br/portal/. Acessos em: 13 set. 2020.

PIORE, Michael J. The dual labor Market: theory and implications. In: GRUSKY, David B.

Social stratification: class, race and gender in sociological perspective. Philadelphia:

Westview Press, 2008. Cap. 56.

RIO DE JANEIRO. Secretaria de Inspeção do Trabalho. Ministério do Trabalho e Emprego. Nota Técnica no 36: competência para fixação dos 'quadros' de trabalhadores portuários avulsos nos portos organizados. Rio de Janeiro: Unidade Especial de Inspeção do Trabalho Portuário e Aquaviário, 2001. 4 p.

RODRIGUES, Leôncio Martins. Partidos e sindicatos: Escritos de Sociologia Política. São Paulo: Ática. 1991.

SANTA CATARINA. Convenção Coletiva 2010/2011 - $1^{a}$ parte. Convenção Coletiva de Trabalho Sindicato dos Conferentes de Carga e Descarga nos Portos de Itajaí e Florianópolis. Itajaí, 08 de julho de 2011. Disponível em: http://www.tallyman.com.br/news/newsVer. php?id=186\#: :text=Par\%C3\%A1 grafo $\% 203 \%$ C2\%BA $\% 20 \% 2 \mathrm{D} \% 20$ Havendo $\% 20$ falta $\% 20 \mathrm{de}$ ,se\%20engajarem\%20para\%20o\%20trabalho\%2C. Acesso em: 13 set. 2020.

SARTI, Ingrid. Porto vermelho: os estivadores santistas no sindicato e na política. Rio de Janeiro: Paz e Terra, 1981.

SENNETT, Richard. A Corrosão do caráter: consequências pessoais do trabalho no novo capitalismo. Rio de Janeiro: Record, 1999.

SILVA, Fernando Teixeira da. A carga e a culpa. São Paulo: Hucitec, 1995.

ZOTTO, Tânia Cristina. O trabalho de estiva. Modernização x tradição: os desafios da tecnologia e da gestão no cais. São Paulo: LTr, 2002.

Recebido em 03/12/2019.

Aprovado em 12/07/2020. 